\title{
Vertical distribution of sub-micron aerosol chemical composition from North-Western Europe and the North-East Atlantic
}

\author{
W.T. Morgan ${ }^{1}$, J.D. Allan ${ }^{1,2}$, K.N. Bower ${ }^{1}$, G. Capes ${ }^{1}$, J. Crosier ${ }^{1,2}$, \\ P.I. Williams ${ }^{1,2}$ and H. Coe ${ }^{1}$ \\ 1. Centre for Atmospheric Science, University of Manchester, Manchester, UK \\ 2. National Centre for Atmospheric Science, University of Manchester, UK \\ Correspondance to: W. T. Morgan (william.morgan@ postgrad.manchester.ac.uk) \\ Supplementary material for the maunscript published in ACP.
}



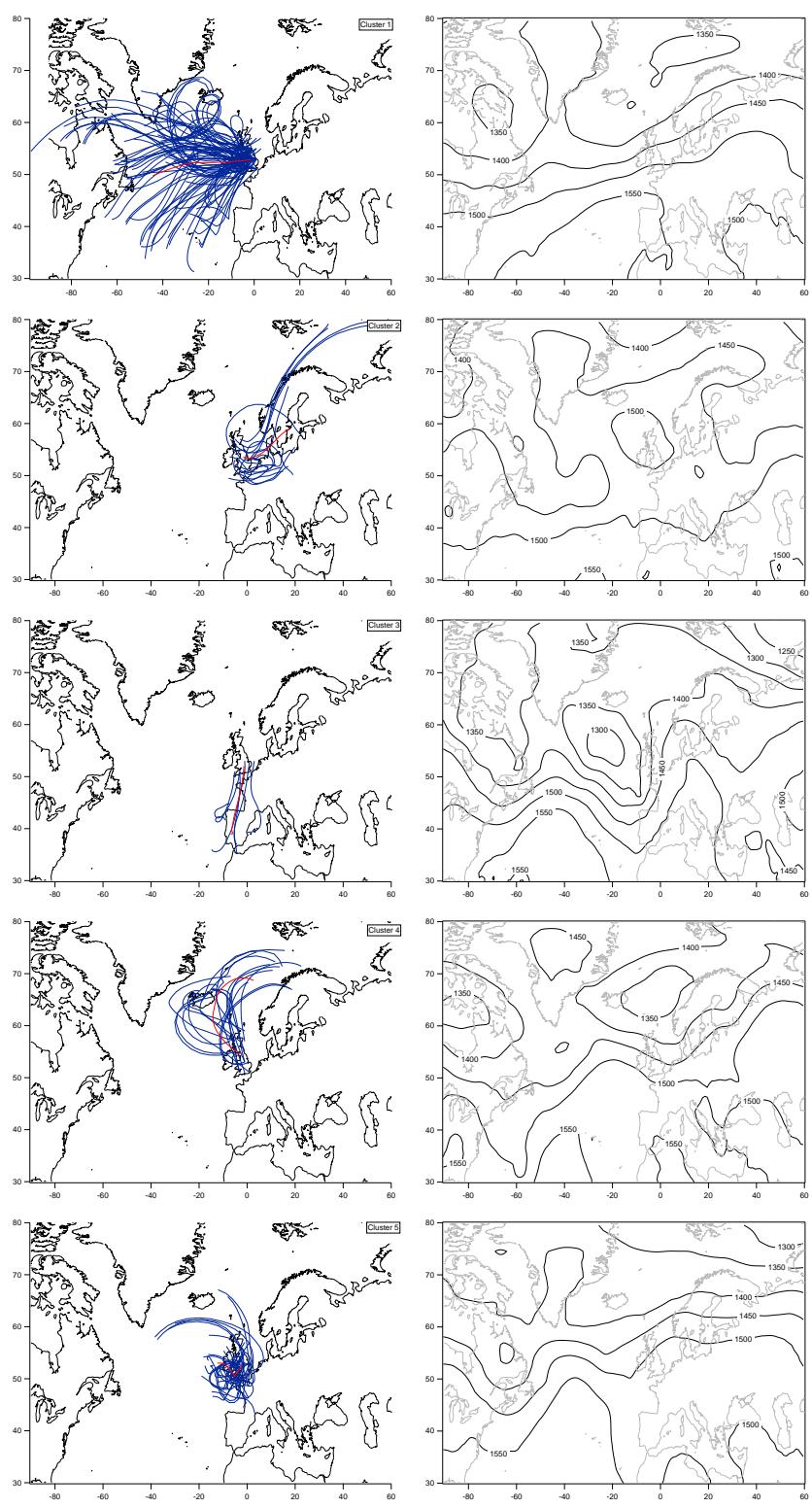

Figure S1: Maps of all back trajectories for each cluster along with the mean trajectory (red line). Also shown are average ECMWF* $850 \mathrm{hPa}$ geopotential height fields based on a 2.5 by 2.5 horizontal grid. *European Centre for Medium-Range Weather Forecasts. ECMWF Operational Analysis data, [Internet]. BADC, .2006-2008.

Available from http://badc.nerc.ac.uk/data/ecmwf-op/ 


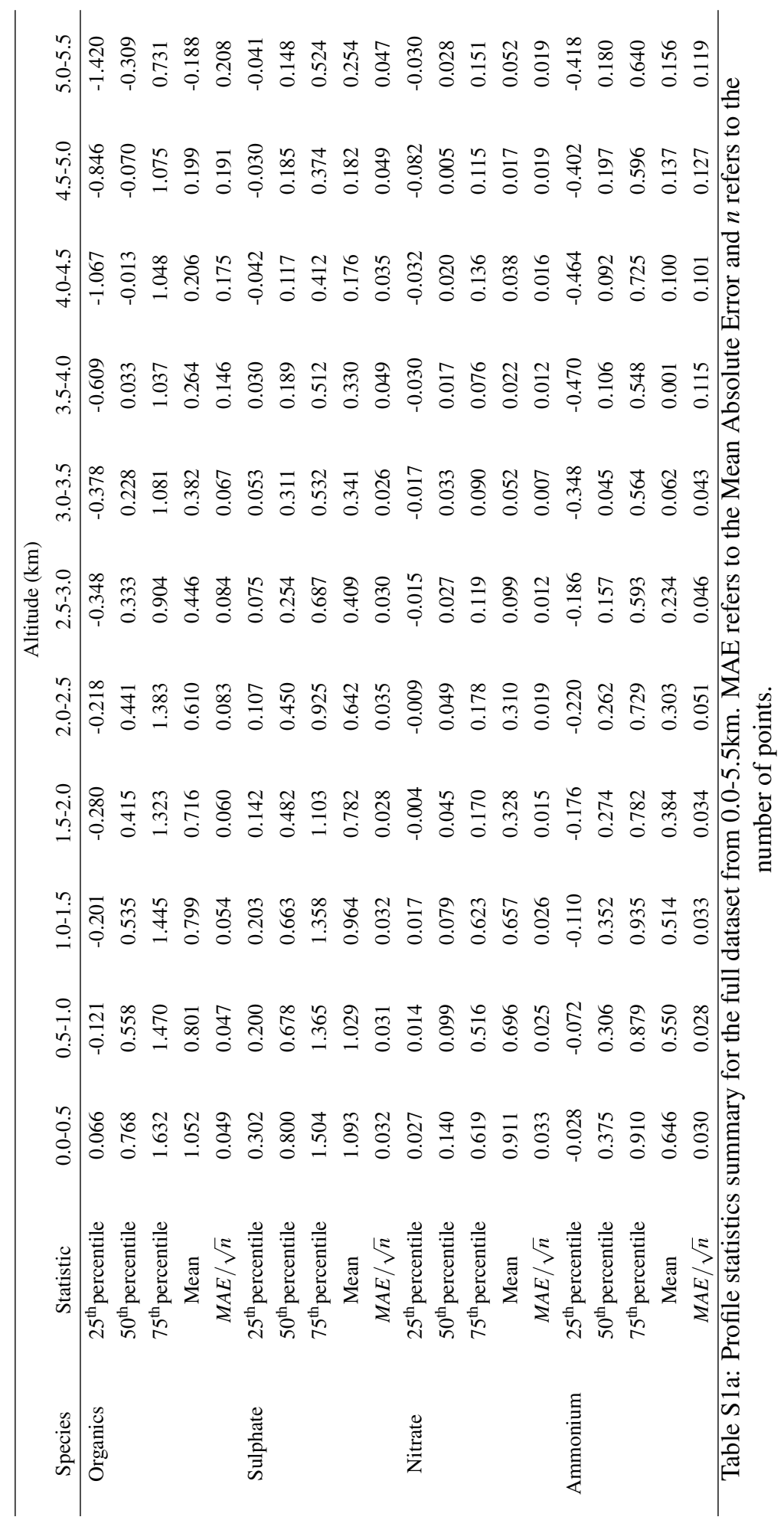




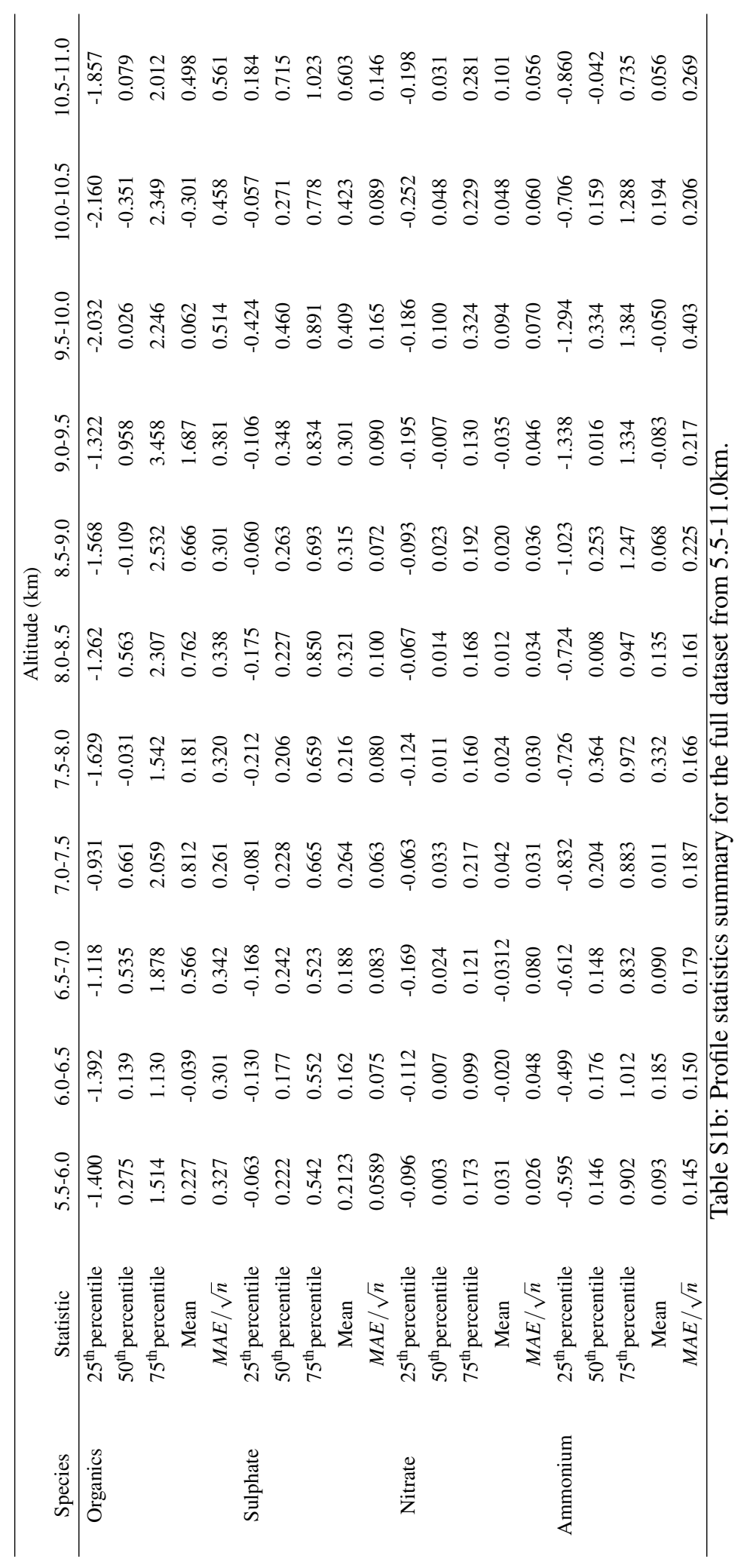




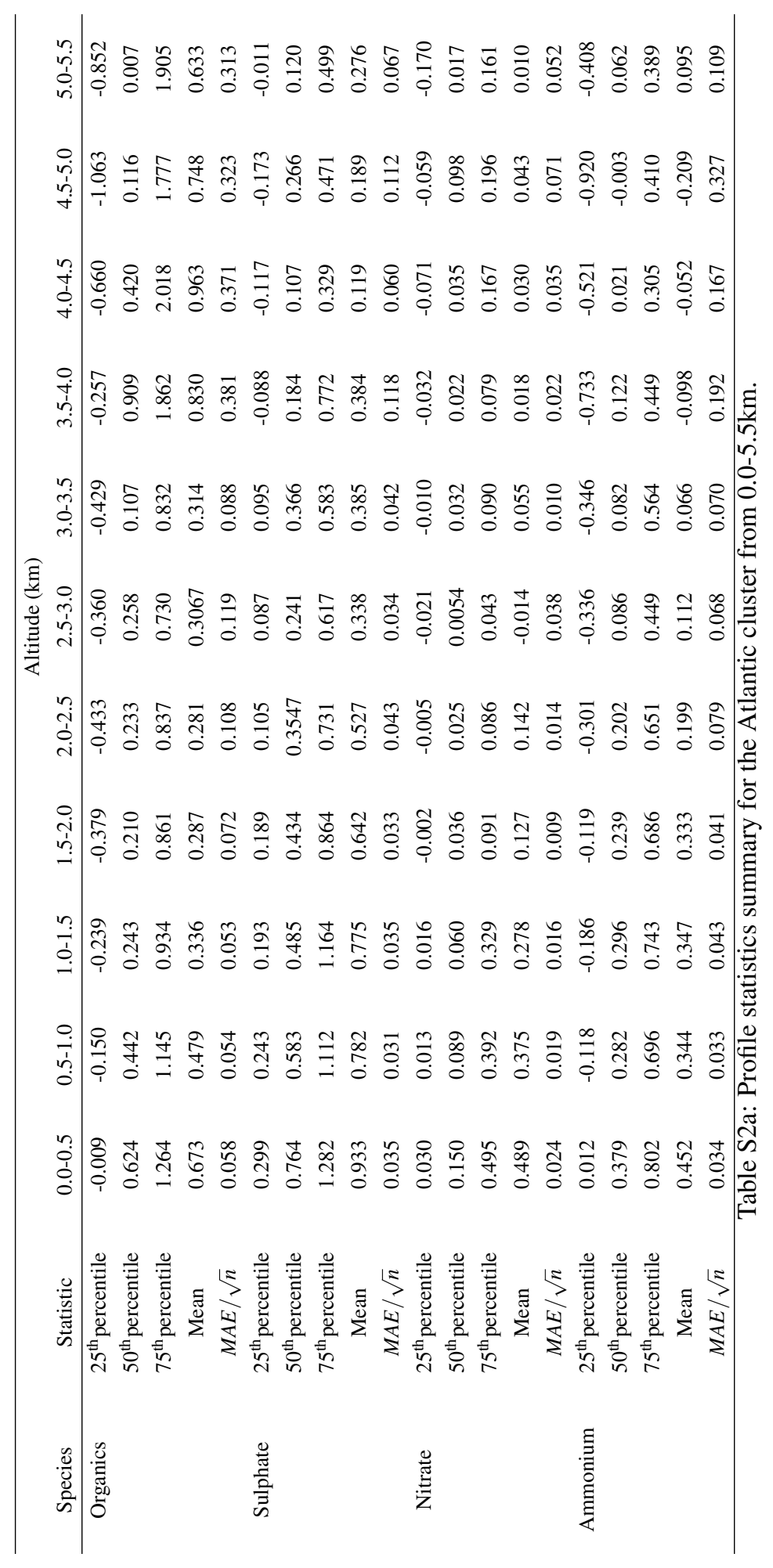




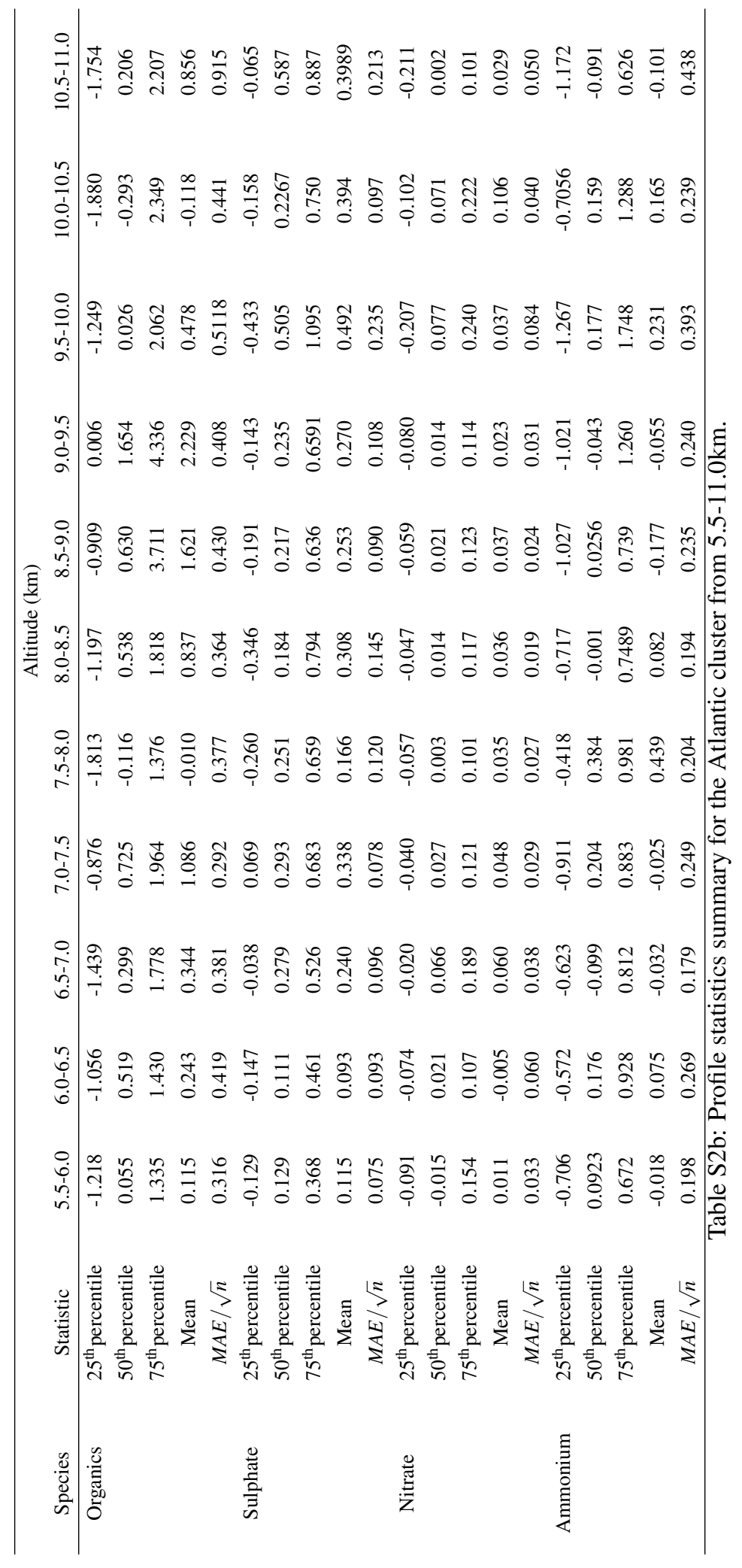




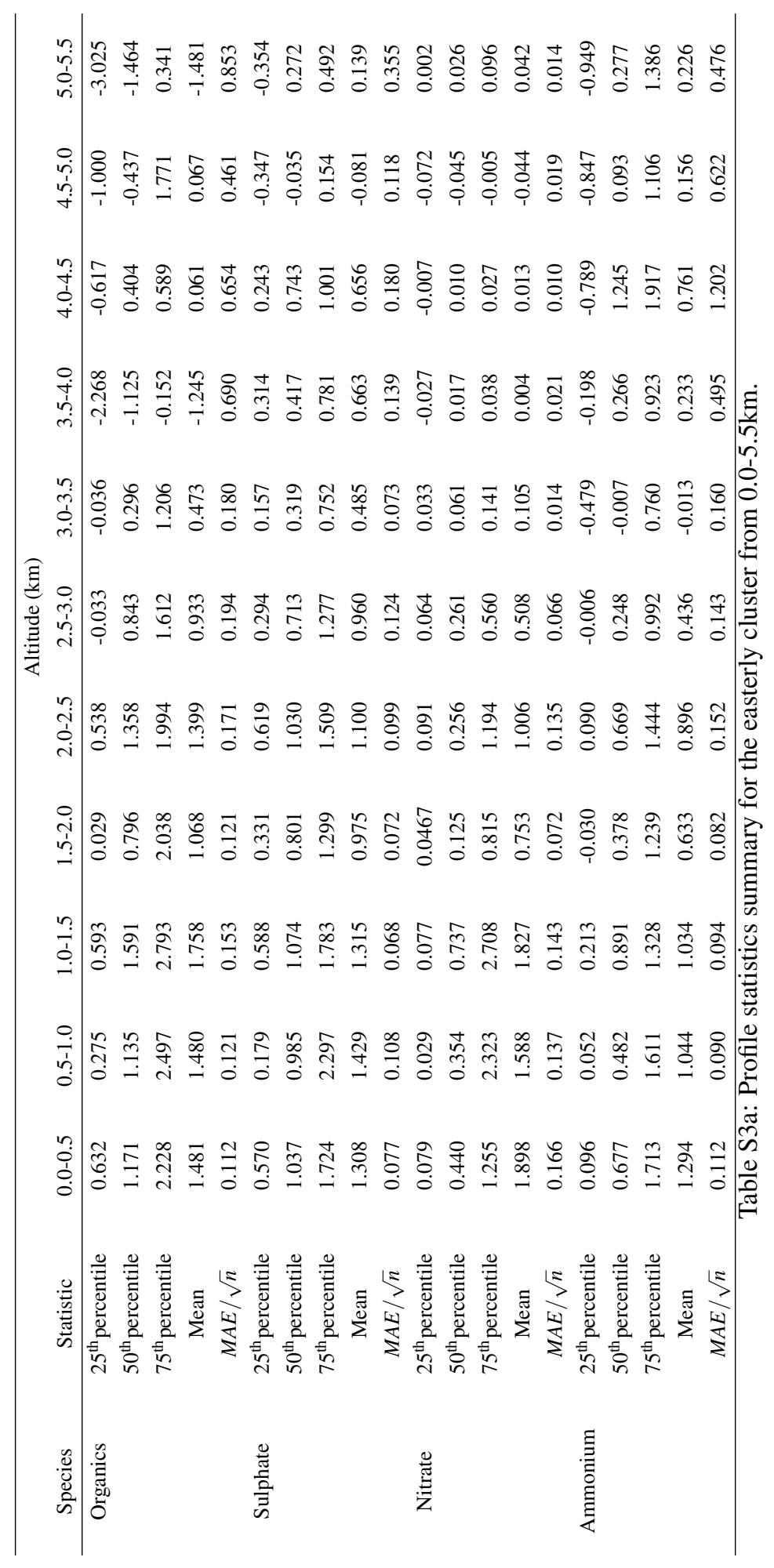




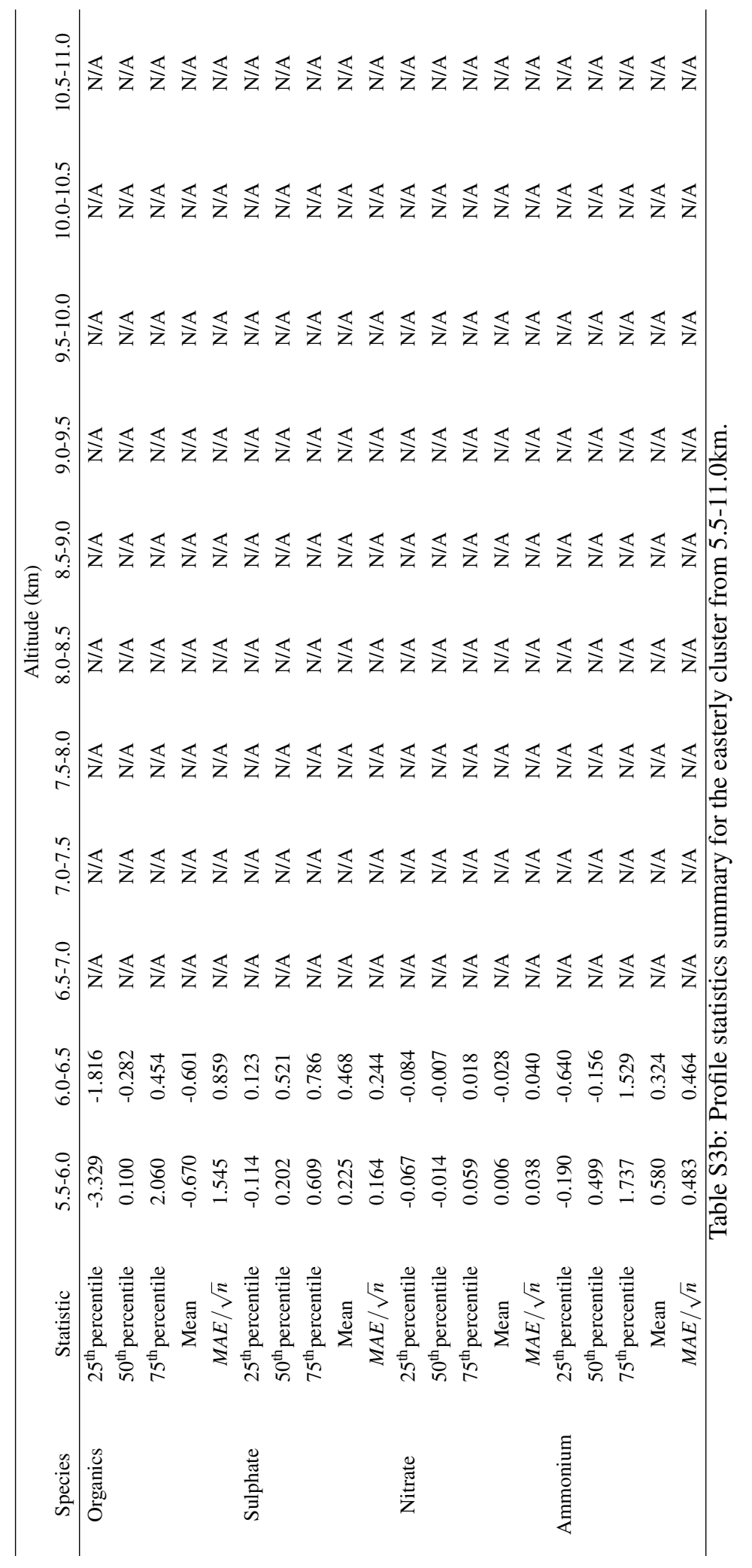




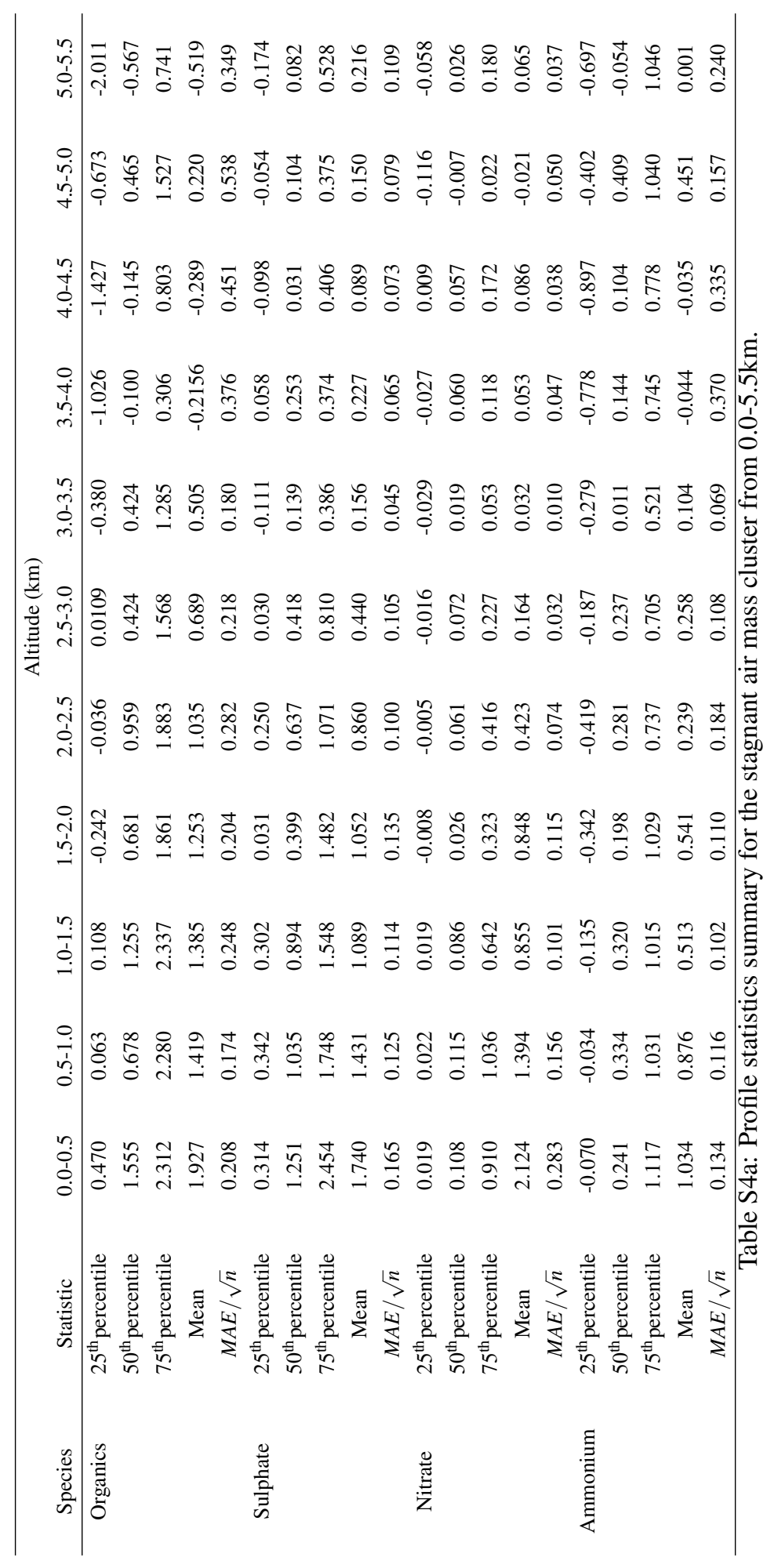




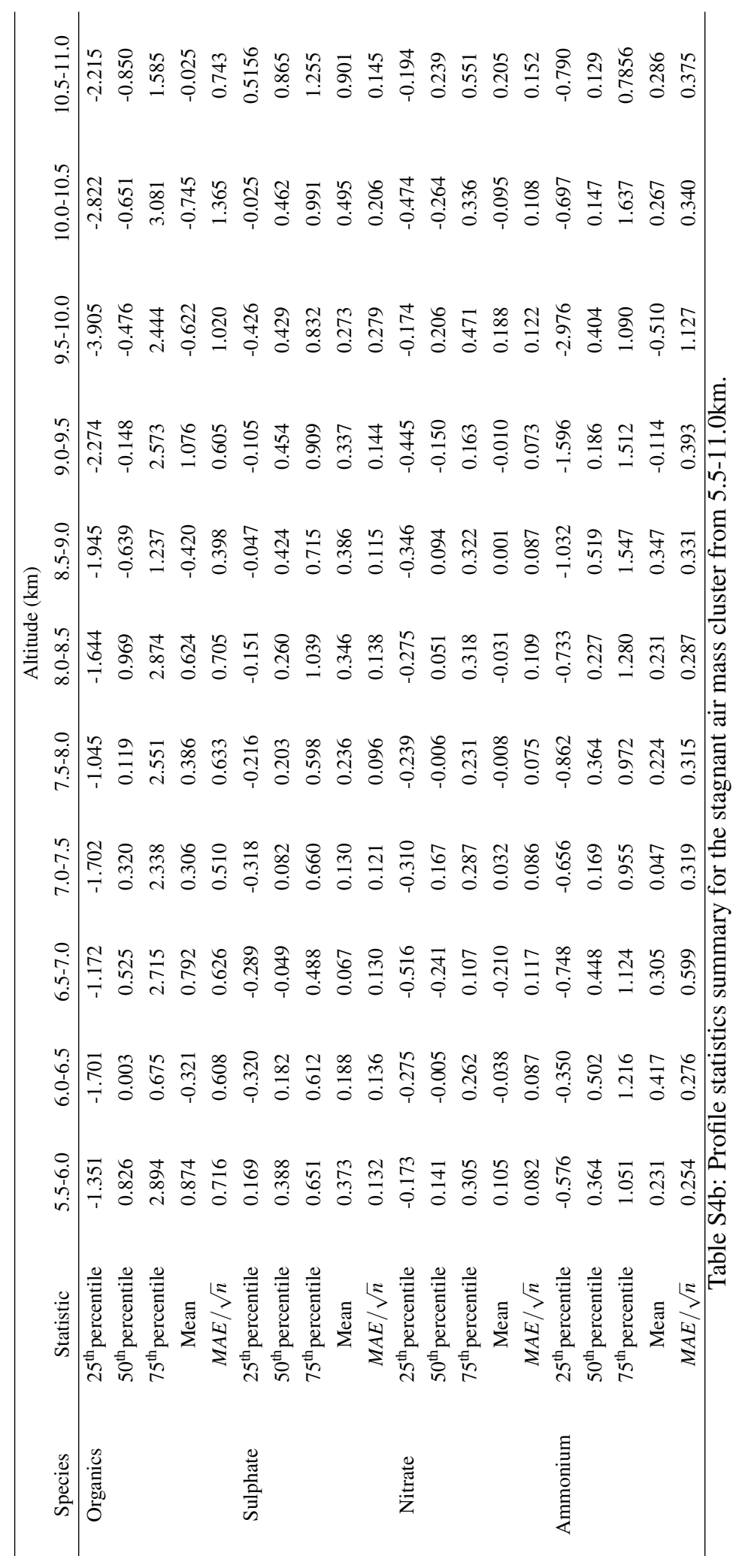




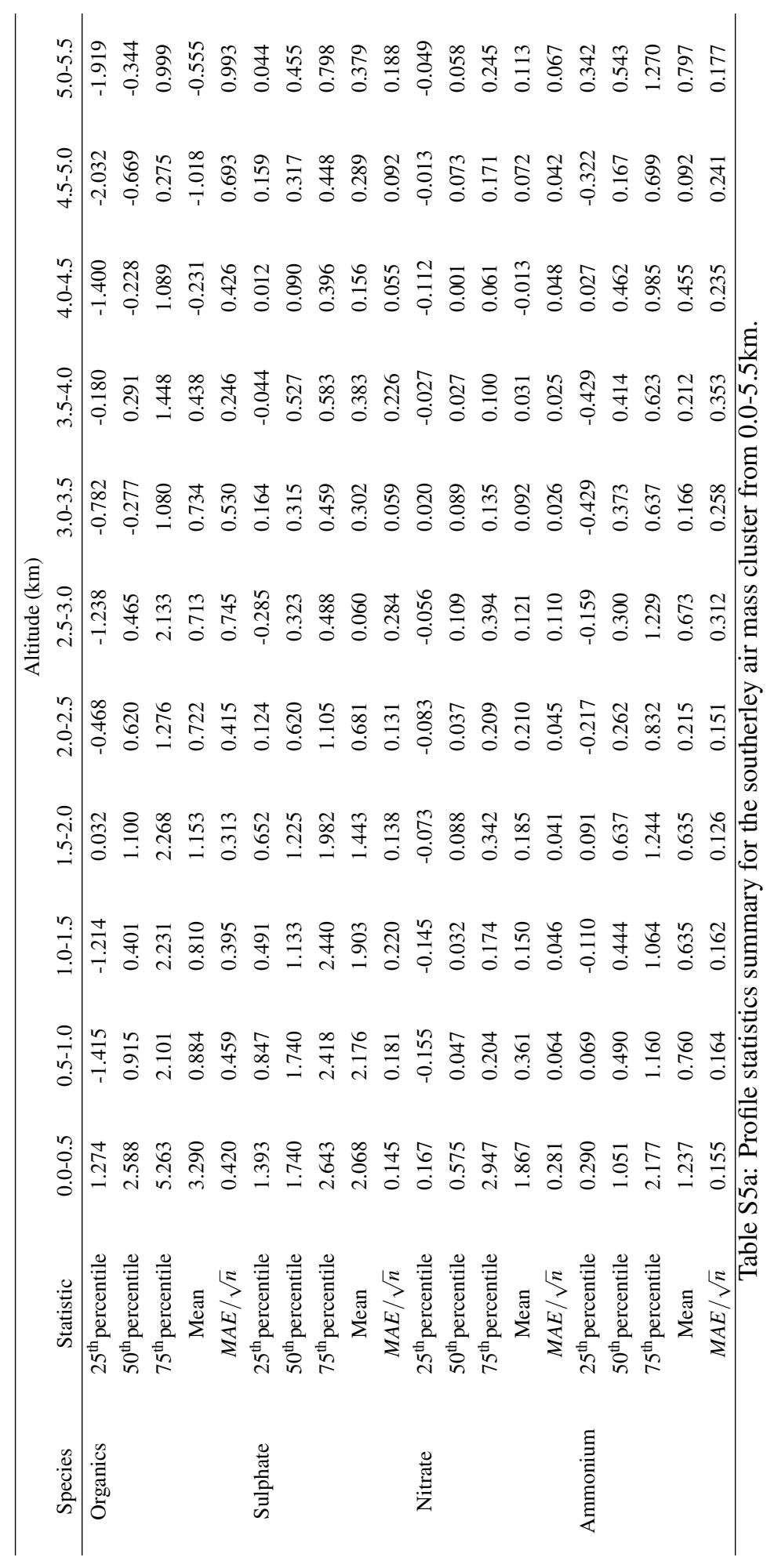




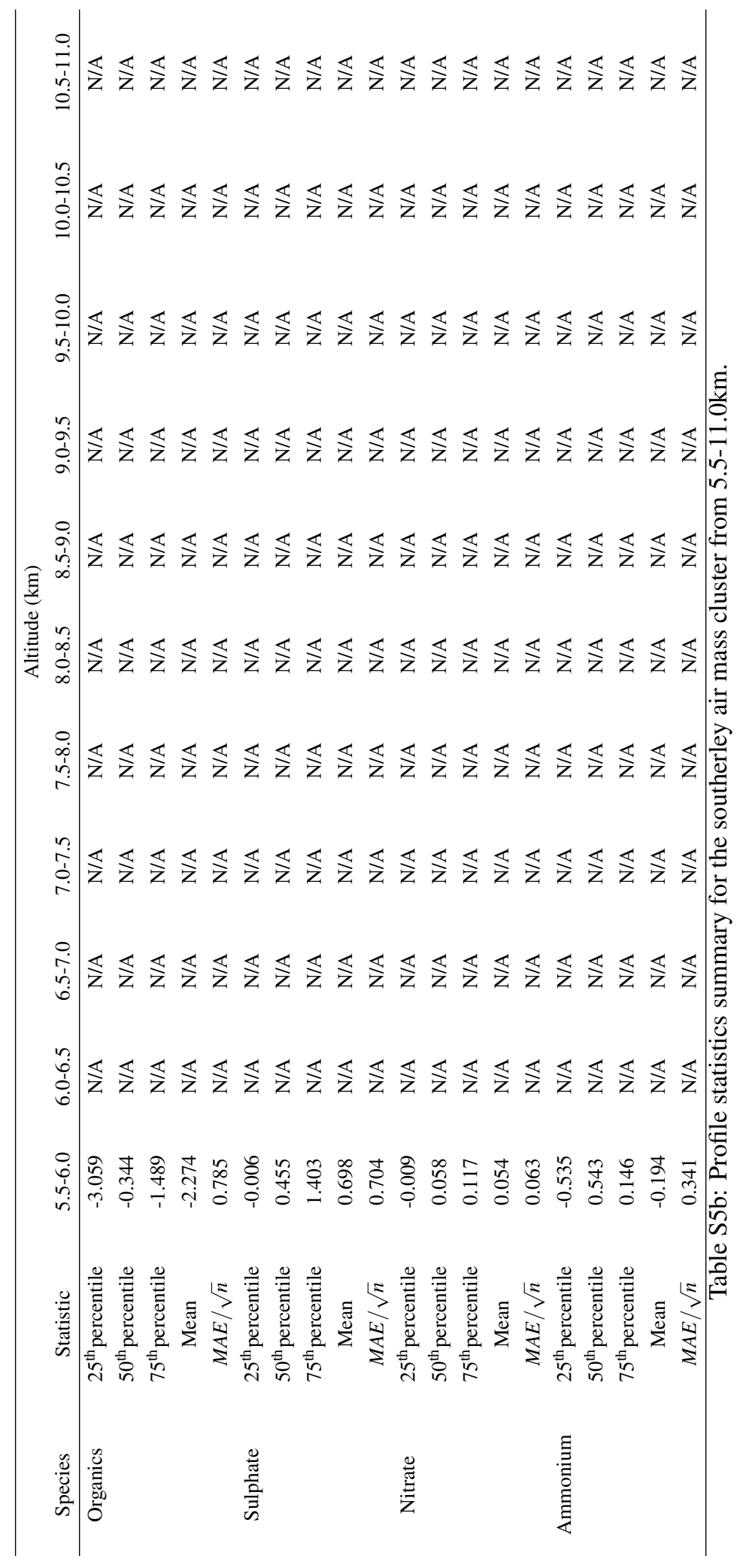




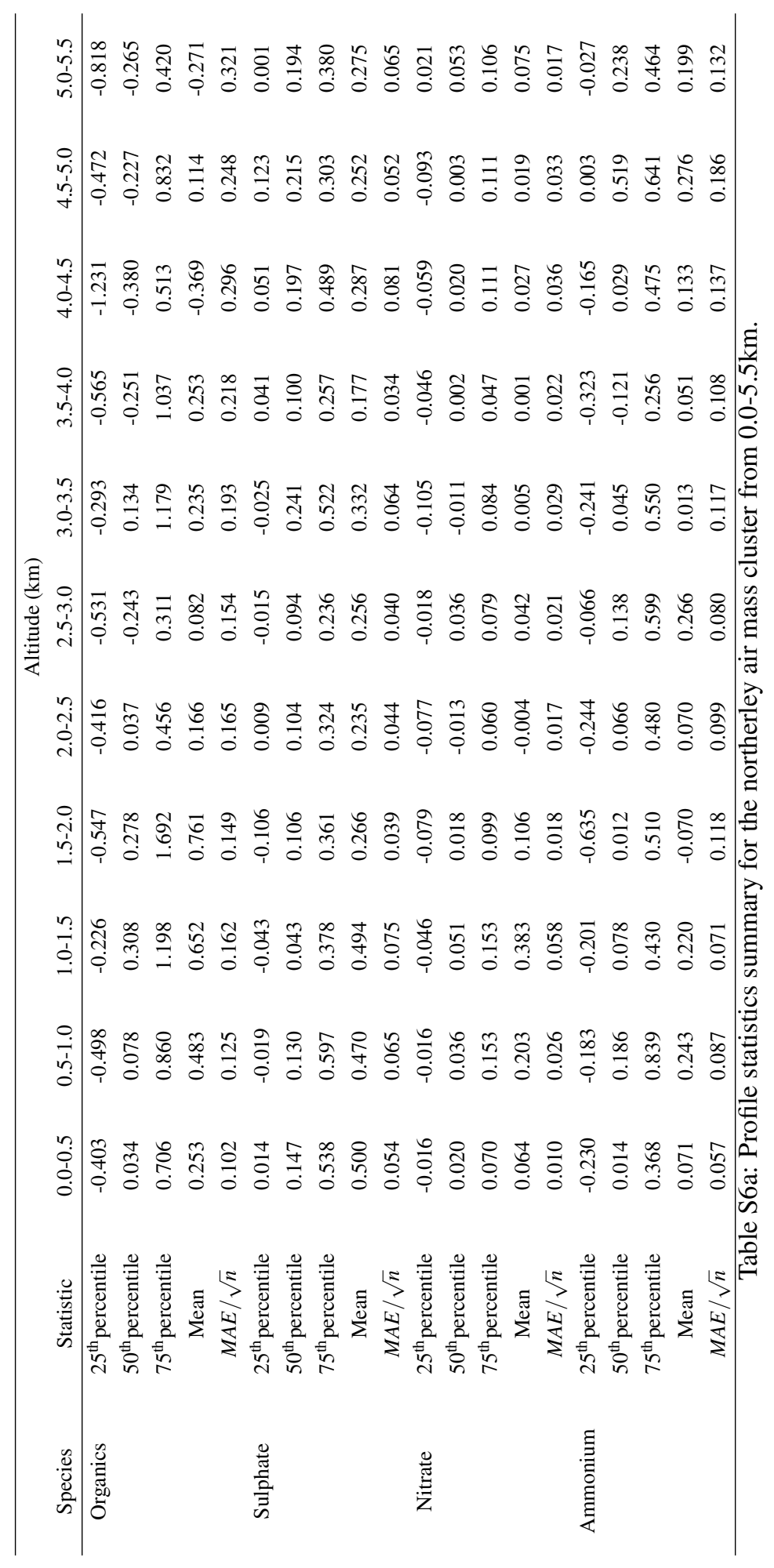




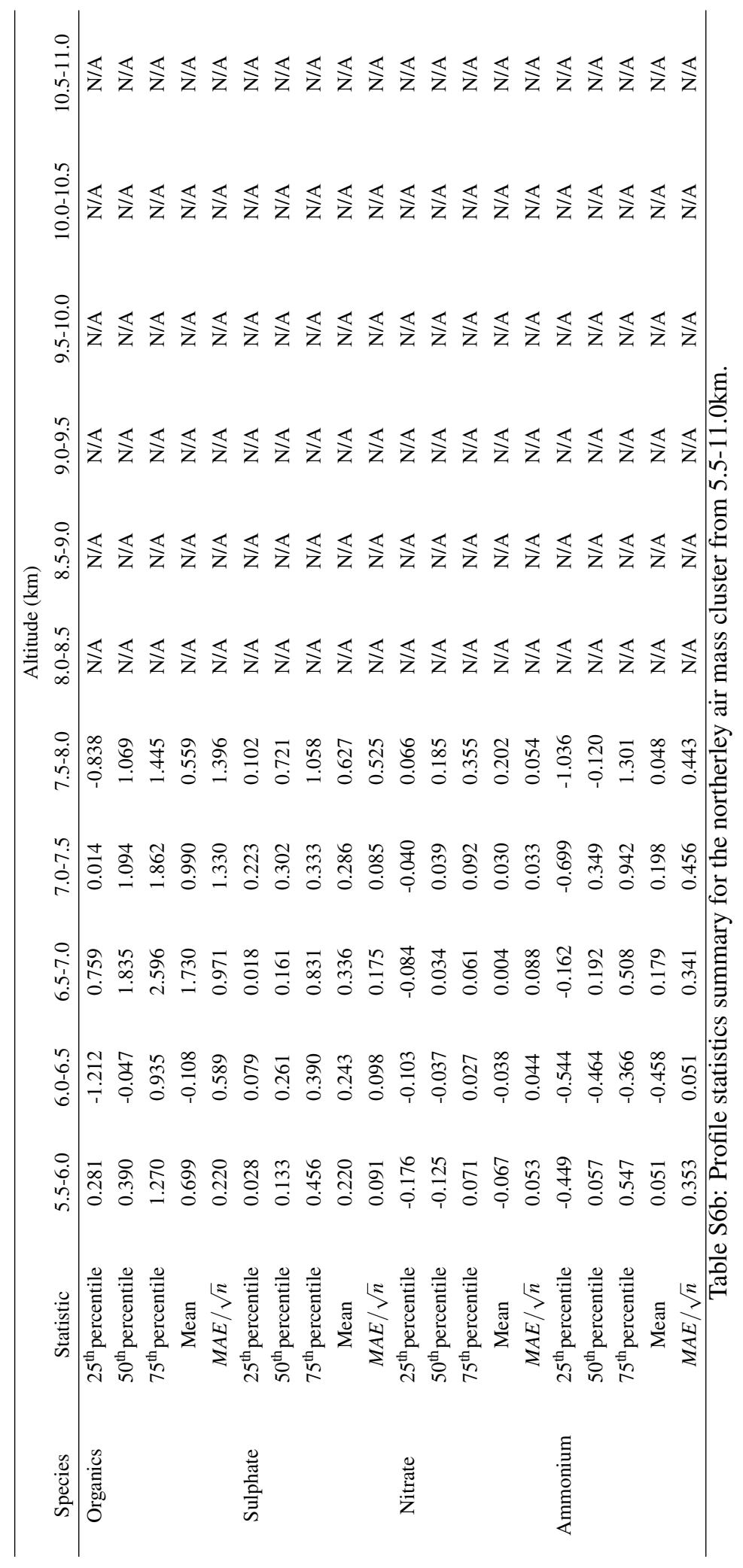

